\title{
A definitive diagnosis of primary Hodgkin lymphoma on endoscopic biopsy material utilizing in-depth immunohistochemical analysis
}

\author{
Garnet Horne $M D^{1}$, Shaun $A C$ Medlicott $M D^{1}$, Adnan Mansoor MD ${ }^{1}$, \\ Johan Lategan $\mathrm{MD}^{2}$, Raymond Lai $\mathrm{MD}^{3}, \mathrm{P}$ Beck $\mathrm{MD}^{2}$
}

\begin{abstract}
G Horne, SAC Medlicott, A Mansoor, J Lategan, R Lai, P Beck. A definitive diagnosis of primary Hodgkin lymphoma on endoscopic biopsy material utilizing in-depth immunohistochemical analysis. Can J Gastroenterol 2007;21(3):185-188.
\end{abstract}

The esophagus and stomach can be primary sites for Hodgkin lymphoma (HL). The pathognomonic feature of HL is the ReedSternberg cell. Because these cells can be rare in HL tumours, biopsies obtained via endoscopy are usually inadequate for establishing a definitive diagnosis. A case of a gastroesophageal junction primary $\mathrm{HL}$ is presented that was diagnosed on endoscopic biopsy material with the assistance of the immunohistochemical stains PAX5 and MUM1 which verified the presence of Reed-Sternberg cells. The patient was effectively treated for HL and avoided traditional laparotomy or thoracotomy procedures to obtain the diagnosis. This advanced immunohistochemical approach should be the standard in the diagnosis of primary gastrointestinal HL. An endoscopy-based approach should obviate more invasive, open biopsy procedures for establishing HL diagnosis.

\section{Un diagnostic définitif de maladie de Hodgkin primaire au moyen de l'analyse immunohistochimique d'un prélèvement endoscopique}

\begin{abstract}
L'œsophage et l'estomac peuvent être des sièges primaires de maladie de Hodgkin (MH). Les cellules de Reed-Sternberg sont la caractéristique phatognomonique de la MH. Puisque ces cellules peuvent être rares dans les tumeurs de $\mathrm{MH}$, les biopsies obtenues par endoscopie ne permettent généralement pas d'établir un diagnostic définitif. Est présenté un cas de $\mathrm{MH}$ primaire à la jonction gastro-œsophagienne diagnostiqué par coloration immunohistochimique PAX5 et MUM1 d'un prélèvement endoscopique, qui a démontré la présence de cellules de Reed-Sternberg. Le patient a subi un traitement efficace contre la MH et évité les interventions diagnostiques classiques par laparatomie ou thoracotomie. Cette démarche immunohistochimique perfectionnée devrait constituer la norme pour diagnostiquer la $\mathrm{MH}$ gastro-intestinale primaire. Une démarche endoscopique éviterait les biopsies ouvertes plus effractives pour confirmer un diagnostic de MH.
\end{abstract}

Key Words: Gastroesophageal junction; Hodgkin lymphoma; MUM1; PAX5

$\mathrm{T}$ he gastrointestinal (GI) tract is a common site for extranodal non-Hodgkin lymphoma (NHL). However, primary $\mathrm{HL}$ of the stomach or esophagus is an extremely remote scenario, accounting for fewer than $1 \%$ of lymphomas in these organs $(1,2)$. The diagnosis requires exclusion of undifferentiated carcinomas, epithelioid sarcomas and commonly NHLs, especially diffuse large B cell lymphomas (DLBL), natural killer/T cell lymphomas and anaplastic large cell lymphomas (ALCL) $(3,4)$. Ancillary studies including gene rearrangement, flow cytometry and immunohistochemical analysis of the tumour are critical for confirming the diagnosis.

Most published examples of gastroesophageal HL were verified only after surgical resection $(3,5)$. We report a gastroesophageal junction (GEJ) primary HL and the utilization of the immunohistochemical markers, PAX5 and MUM1. These antibodies can help delineate the pathognomonic HL Reed-Sternberg (RS) cells especially when assessing limited biopsy material. The most common cause of HL localizing to the wall of viscera would be contiguous invasion of primary

lymph node disease. However, a positive endoscopic biopsy of HL may provide credence for a GI tract mucosa origin. We advocate that transmucosal biopsy material must be diagnostic if $\mathrm{HL}$ is to qualify as a GI primary neoplasm.

\section{CASE PRESENTATION}

A previously healthy 33-year-old man developed progressive dysphagia and had an involuntary weight loss of $4.5 \mathrm{~kg}$ over the past six months. Esophagogastroduodenoscopy identified an ulcerated mass $(45 \mathrm{~cm})$ of the GEJ (Figure 1). The lesion extended $2 \mathrm{~cm}$ into the distal esophagus and provided resistance upon intubating the stomach. Contiguous involvement of the cardia was obvious on retroflexed views. A computed tomography scan of the chest and abdomen revealed at least a $6 \mathrm{~cm} \times 6 \mathrm{~cm}$ ill-marginated soft tissue mass encasing the distal esophagus and extending caudally into the stomach cardia and fundus (Figure 2). The mass was devoid of calcification and contrast enhancement. The proximal and mid-esophagus, as well as the distal fundus and antrum, were unremarkable.

${ }^{1}$ Department of Pathology and Laboratory Medicine; ${ }^{2}$ Department of Internal Medicine, Peter Lougheed Centre, University of Calgary, Calgary;

${ }^{3}$ Cross Cancer Institute, University of Alberta, Edmonton, Alberta

Correspondence and reprints: Dr Shaun AC Medlicott, Calgary Laboratory Services, Peter Lougheed Centre, 3500-26 Street North East,

Calgary, Alberta T1Y 6J4. Telephone 403-943-4907, fax 403-291-2931, e-mail shaun.medlicott@cls.ab.ca

Received for publication February 8, 2006. Accepted March 5, 2006 

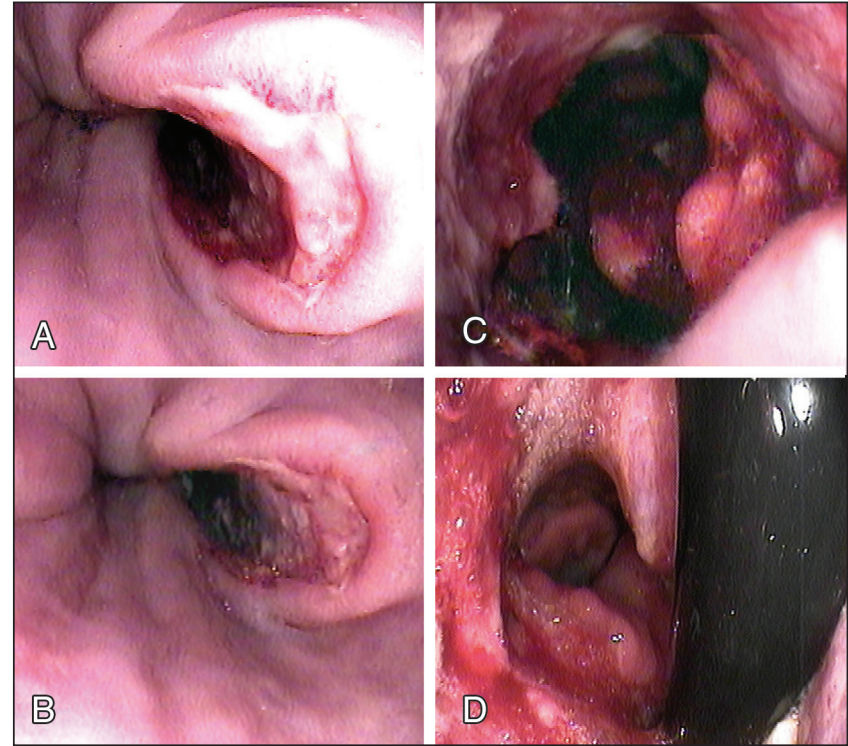

Figure 1) Esophagogastroduodenoscopy identified an ulcerating gastroesophageal junction mass $(45 \mathrm{~cm})$ that resisted intubation. Esophagus (A,B) and stomach (C,D)

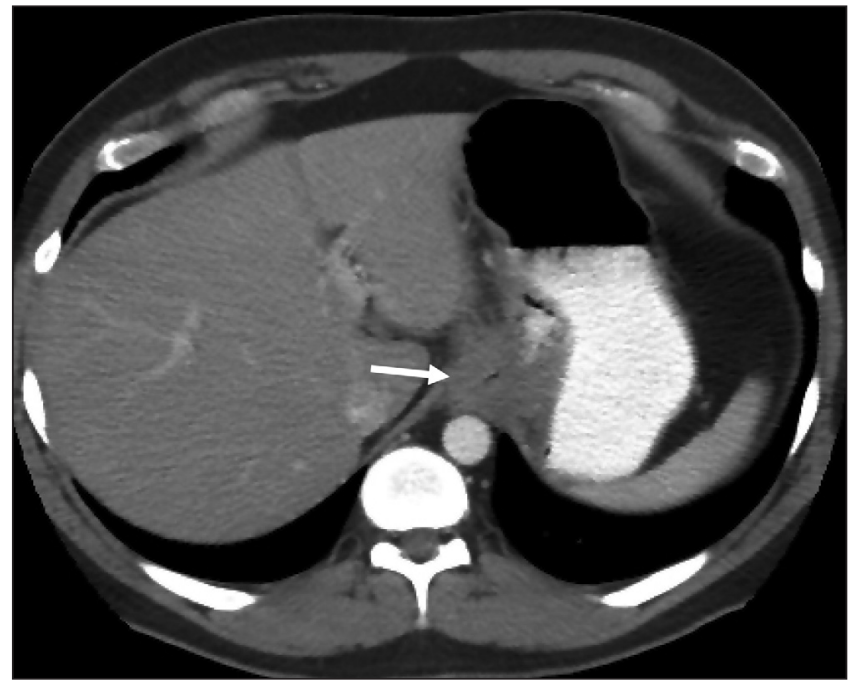

Figure 2) Computed tomography scan delineated a bulky ill-defined mass (arrow) circumscribing the distal esophagus

Computed tomography imaging also identified enlarged lymph nodes of the lesser curve of the stomach and peripancreatic and subdiaphragmatic periaortic areas. No lymphadenopathy was identified in the supraclavicular, axillary and mediastinal regions. The liver and spleen were normal.

A repeat esophagogastroduodenoscopy one week later procured tumour for flow cytometry analysis that excluded a B and $\mathrm{T}$ cell monoclonal proliferation, as expected in HL. A bone marrow biopsy was negative for malignancy. No immunodeficiency illness or predisposition was discerned on subsequent investigations.

\section{Immunohistochemistry}

\section{METHODS}

Histological sections $4 \mu \mathrm{m}$ thick were stained using the Envision antimouse and antirabbit antibodies (Dako Canada Inc) and the diaminobenzidine-Plus kit (Dako Canada Inc). Positive and

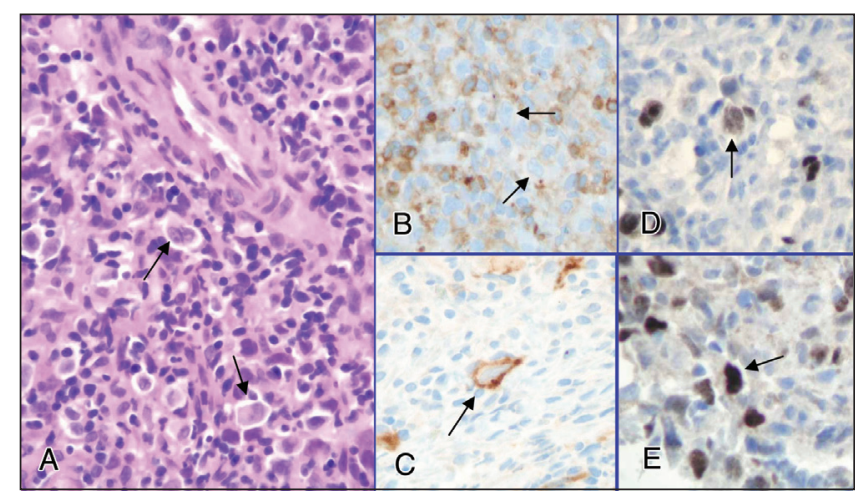

Figure 3) Small foci of tumour had rare Reed-Sternberg cells (arrows), circumscribed by reactive lymphocytes, plasma cells and eosinophils. Hematoxylin and eosin (A); Reed-Sternberg cells are CD45-negative (B); CD30-positive (C); weakly PAX5-positive (D) and MUM1-positive (E). Original magnification $\times 400$

negative controls were run in parallel with test material. Antibodies included: CD45 and ALK-1 (diluted 1:400 and 1:500, respectively, Zymed Laboratories Inc, USA); CD20, Ki-67, kappa, lambda, MUM1, CD8, HMB-45, CD117 and epithelial membrane antigen (diluted 1:500, 1:100, 1:10,000, 1:10,000, 1:25, 1:100, 1:200, 1:200 and 1:200, respectively, Dako Canada Inc); CD30, CD15, bcl-2, vimentin and S-100 were prediluted, AE1/3 (diluted 1:20, Ventana Medical Systems Inc, USA); CD2, CD4 and bcl-6 (diluted 1:100, 1:50 and 1:25, respectively, Vector Laboratories, USA); CD3 and CD5 (diluted 1:200 and 1:40, respectively, Lab Vision Co, USA); CD10 (diluted 1:100, Research Diagnostics Inc, USA); PAX5 (diluted 1:50, Becton Dickinson and Co, USA); actin (diluted 1:6000, Sigma-Aldrich Co, USA); cytokeratin 7, cytokeratin 20 and cytokeratin 5/6 (diluted 1:200, 1:20 and 1:25, respectively, Cell Marque Co, USA); cytokeratin 19 (diluted 1:25, Biogenex, USA); and pancytokeratin (in-house).

In situ hybridization for Epstein-Barr virus encoded RNA Epstein-Barr virus messenger RNA detection in paraffin blocks utilized the Dako GenPoint In situ Detection Kit (Dako Canada Inc) with Epstein-Barr virus encoded RNA (EBER)-1 and EBER-2 oligonucleotides (Dako Canada Inc, Y017) as probes. The probes were labelled with diaminobenzidine chromogen. Known positive and negative controls were run in parallel.

\section{RESULTS}

The initial endoscopy procured mucosal fragments with focally intact squamous and oxyntic epithelium of the esophagus and stomach. The lamina propria and submucosa were expanded by sheets of noncohesive anaplastic cells. Some cells had reniform nuclei, others had bizarre multilobated nuclei. Extremely rare cells had bilobed mirror-image nuclei approaching the classic morphology of RS cells (Figure 3). No hallmark cells were identified. The process was compatible with lymphoma. An abundance of anaplastic cells detracted from a diagnosis of HL but the immunohistochemistry (IHC) profile of positive CD30 and negative CD45, CD20, ALK-1 and T cell (CD2, CD3, CD4, CD5 and CD8) antibody staining was complementary. In the absence of CD15 and EMA staining, a definitive diagnosis was not issued. In situ hybridization revealed strong nuclear staining for EBER in the 
anaplastic cells. A repeat biopsy procured fresh tissue for flow cytometry assessment. The subsequent material had similar tumour morphology, IHC and EBER staining patterns. Additional IHC analysis revealed positive MUM1 and weakly positive PAX5 staining of anaplastic cells. Flow cytometry did not identify a monoclonal B or T cell population. All of these findings were compatible with HL. Gene rearrangement analysis by polymerase chain reaction identified a polyclonal immunoglobulin heavy chain and a $\mathrm{T}$ cell receptor pattern, excluding a B and T cell NHL.

On rendering an initial diagnosis of lymphoma, chemotherapy was implemented. There was an immediate improvement in the progressive dysphagia, and tumour bulk diminished. The patient had a complete radiological response six months after the diagnosis was established.

\section{DISCUSSION}

We have described a rare case of primary GEJ HL. Lymphoma is foremost a malignancy of lymph nodes with over $66 \%$ of NHLs and almost all HLs presenting as a lymphadenopathy (6). The GI tract is the most common site for extranodal lymphoma, especially in the stomach $(6,7)$. Criteria for the diagnosis of primary GI lymphoma were established by Dawson et al (8) in 1961 and are still in use (1,3,7). Criteria included the location of the bulk of the lymphoma in the digestive tract, an absence of superficial and mediastinal lymphadenopathy, an absence of organomegaly, no bone marrow involvement and a normal peripheral complete blood count.

Gastric HL is extremely rare, accounting for fewer than $1 \%$ of all gastric primary lymphoma $(1,2)$. The malignancy has a slight male predominance ratio of $1.2: 1$, a peak incidence in the fifth to sixth decades and may have a propensity for the antrum and pylorus $(1,3,7)$. Presenting symptoms include: upper abdominal pain, nausea, vomiting, GI bleeding and weight loss $(3,7)$. Our patient satisfied the criteria for a GI primary HL, albeit symptoms of dysphagia are not typical for gastric HL.

Because primary gastric HL is a remote entity, the diagnosis requires validation through ancillary investigation $(1,3,7)$. Historically, an accurate diagnosis of gastric HL is not established on mucosal biopsies procured by endoscopy (3). Ogawa et al (3) reported that of the 100 gastric HL cases between 1924 and 1993 (before surgical resection), accurate diagnoses were established in only three cases. There was no speculation as to why preoperative diagnostic material was difficult to ascertain. Despite having original positive mucosal biopsy material in our case, we requested a second endoscopic biopsy for ancillary investigations that confirmed the diagnosis of HL. Certainly, technological advances in imaging methodologies, endoscopy and ancillary testing should accommodate successful tumour sampling by minimally invasive techniques.

HL of the esophagus is usually a contiguous extension of an adjacent lymph node or gastric primary malignancy $(5,9)$. Primary esophagus HL is an extremely rare lesion with a propensity for the mid- or proximal one-third (5,9-11). A variety of clinical presentations include odynophagia/dysphagia, weight loss, epigastric pain, fullness/bloating, anorexia, nonspecific 'type B' symptoms, aneurysmal dilation of the esophagus and tracheoesophageal fistula (5,9-11). When located in the lower esophagus, $30 \%$ of HLs are complicated by stricture formation (5). Our patient's symptoms more accurately reflected those of a cardia or lower esophageal primary malignancy. The radiological finding of lymphadenopathy in neighbouring lymph nodes is compatible with the expected contiguous dissemination of an HL.

The classic endoscopic appearance of esophageal HL is an ulcerated mass, often indistinguishable from a carcinoma (5). Despite the obvious mucosal embarrassment, repeat endoscopic biopsy, open biopsy or surgical resection is often required to establish a diagnosis $(5,9)$. It has been speculated that endoscopy may be an inadequate procedure for the assessment of HL because the tumour may have an origin deep in the wall of the viscera (5). However, because GI lymphoid tissue is almost exclusive to the mucosa and submucosa, primary lymphoma should be amenable to transmucosal biopsy procedures. A deep mural origin of HL and/or nondiagnostic mucosal biopsy material would confer that primary disease is actually extramural and/or nodal. If a diagnostic mucosal biopsy were a required criterion for confirming HL of GI origin, disease prevalence may be reduced to extremely rare anecdotal cases.

The RS cell is pathognomonic of HL, regardless of tumour location $(2,6)$. These large cells can have various morphologies including uni- or multinucleation, but a prominent eosinophilic inclusion-like nucleolus is standard (6). Cells with similar morphology can be present in a number of processes so that the differential diagnosis of HL includes: ALCL, adult T cell lymphoma, malignant histiocytosis, poorly differentiated carcinoma, sarcoma and melanoma (1-3). Histology and molecular biology analysis are essential for establishing a definitive diagnosis. PAX5 is a pan-B cell antibody that facilitates the exclusion of other lymphoproliferative disorders from HL (12). Specifically, ALCL and other T cell lymphomas are uniformly negative for PAX5, while $97 \%$ of HL RS cells are weakly positive (12). Only $4 \%$ of DLBL have a weak PAX 5 staining pattern because most are strongly positive (12). MUM1 stains $100 \%$ of classic HL RS cells and is much less sensitive for DLBL $(13,14)$. One caveat is that large atypical cells of lymphocyte-predominant HL have been reported to be MUM1-negative (13). Because mucosal biopsy material may lack architectural landmarks typical of HL, confirmation of the diagnosis mandates the use of highly sensitive IHC antibodies for RS cells such as PAX5 and MUM1 to exclude T cell lymphomas and DLBL, respectively.

Contrary to existing literature, we advocate that the transmucosal biopsy should provide diagnostic material for a GEJ HL. Obvious neoplasm in a mucosal biopsy must be a criterion for confirming HL of viscera origin because it detracts from the possibility that the bulk of the disease is actually extramural/in a lymph node. Allocating fresh tissue for the multitude of essential ancillary studies may be jeopardized when HL is not suspected clinically. Thus, repeat endoscopy may not be avoidable in the assessment of such a neoplasm. Architectural features of HL may be limited on mucosal biopsy material and, thus, highly sensitive IHC antibodies such as PAX5 and MUM1 must be used to confirm this remote scenario that could manifest as a gastric or esophageal ulcerating mass.

ACKNOWLEDGEMENT: This material has been submitted in abstract form for poster presentation at the 2006 Canadian Association of Pathologists meeting in St John's, Newfoundland. 


\section{REFERENCES}

1. Venizelos I, Tamiolakis D, Bolioti S, et al. Primary gastric Hodgkin's lymphoma: A case report and review of the literature. Leuk Lymphoma 2005;46:147-50.

2. Morgan PB, Kessel IL, Xiao SY, Colman M. Uncommon presentations of Hodgkin's disease. Case 1. Hodgkin's disease of the jejunum. J Clin Oncol 2004;22:193-5.

3. Ogawa Y, Chung YS, Nakata B, et al. A case of primary Hodgkin's disease of the stomach. J Gastroenterol 1995;30:103-7.

4. Ferry JA. Lymphoid tumours of the GI tract. In: Odze D, Goldblum JR, Crawford JM, eds. Surgical pathology of the GI Tract, Liver, Biliary Tract and Pancreas, 1st edn. Philadelphia: Elsevier, 2004:523-52.

5. Loeb DS, Ribeiro A, Menke DM. Hodgkin's disease of the esophagus: Report of a case. Am J Gastroenterol 1999;94:520-2.

6. Aster JC. Disease of white blood cells, lymph nodes, spleen and thymus. In: Abbas AK, Fausto N, Robbins S, Cotran RS, eds. Robbins Pathologic Basis of Disease, 7th edn. Philadelphia: Elsevier, 2002:686-90.

7. Colucci G, Giotta F, Maiello E, Fucci L, Caruso ML. Primary Hodgkin's disease of the stomach. A case report. Tumori 1992;78:280-2.
8. Dawson IM, Cornes JS, Morson BC. Primary malignant lymphoid tumours of the intestinal tract: Report of 37 cases in a study of factors influencing prognosis. Br J Surg 1961;48:80-94.

9. Coppens E, El Nakadi I, Nagy N, Zalcman M. Primary Hodgkin's lymphoma of the esophagus. Am J Roentgenol 2003;180:1335-7.

10. Njeh M, Yengui N, Tahri N, et al. [Hodgkin's disease with esophageal involvement]. Rev Med Interne 2000;21:893-6.

11. Gelb AB, Medeiros LJ, Chen YY, Weiss LM, Weidner N. Hodgkin's disease of the esophagus. Am J Clin Pathol 1997;108:593-8.

12. Torlakovic E, Torlakovic G, Nguyen PL, Brunning RD, Delabie J. The value of anti-pax-5 immunostaining in routinely fixed and paraffin-embedded sections: A novel pan pre-B and B-cell marker. Am J Surg Pathol 2002;26:1343-50.

13. Carbone A, Gloghini A, Aldinucci D, Gattei V, Dalla-Favera R, Gaidano G. Expression pattern of MUM1/IRF4 in the spectrum of pathology of Hodgkin's disease. Br J Haematol 2002;117:366-72.

14. Tsuboi $\mathrm{K}$, Iida S, Inagaki $\mathrm{H}$, et al. MUM1/IRF4 expression as a frequent event in mature lymphoid malignancies. Leukemia 2000;14:449-56. 


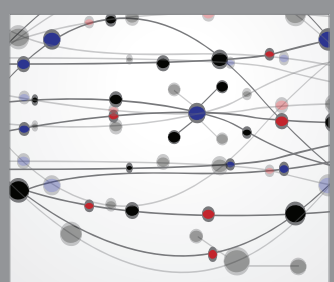

The Scientific World Journal
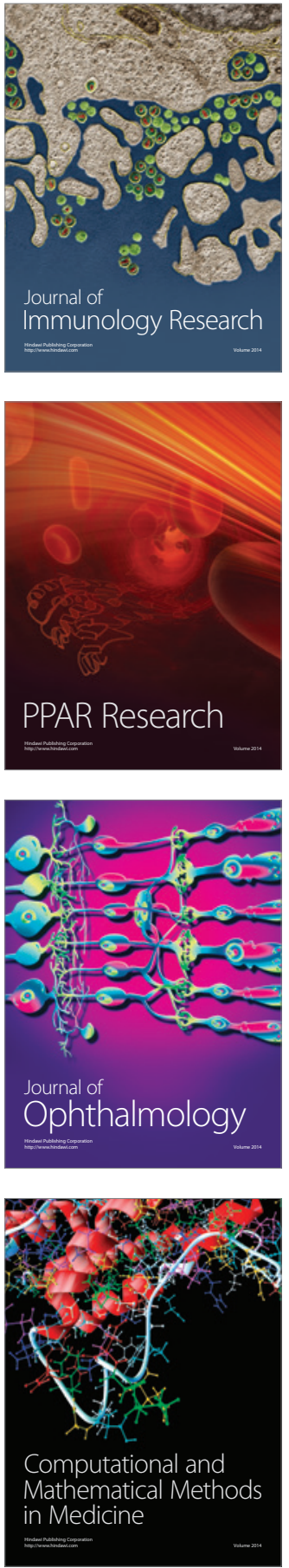

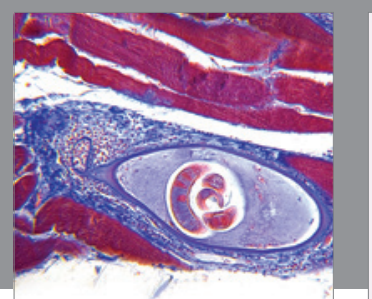

Gastroenterology Research and Practice

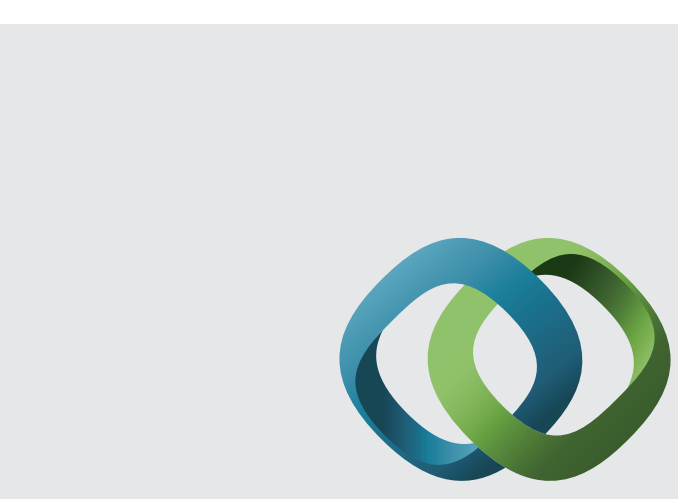

\section{Hindawi}

Submit your manuscripts at

http://www.hindawi.com
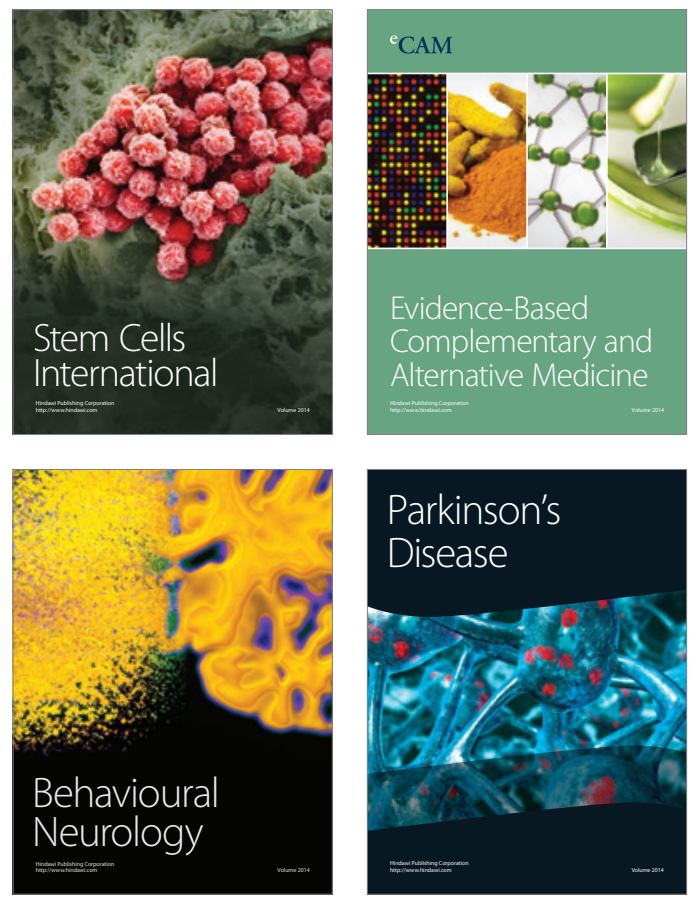
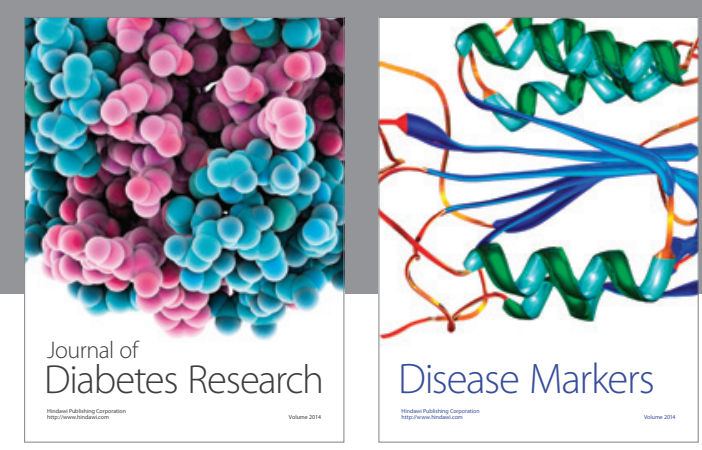

Disease Markers
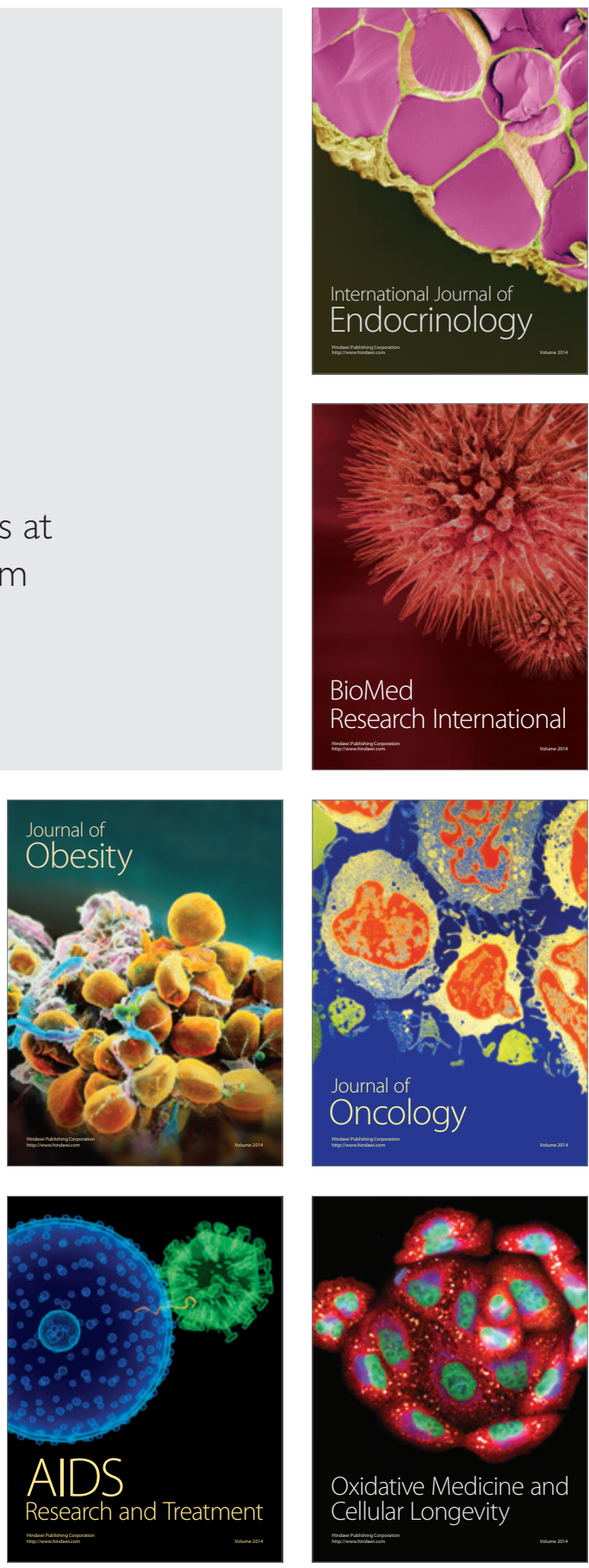